\title{
The Potential of Hydroxyapatite Toothpaste to Prevent Root Caries: A pH-Cycling Study
}

\author{
Bennett Tochukwu Amaechi $\left(\mathbb{D}^{\prime}\right.$ \\ Thais Santiago Phillips' \\ Veronica Evans' \\ Chidera Precious Ugwokaegbe ${ }^{2}$ \\ Minh Nguyet Luong (D) \\ Linda Oge Okoye ${ }^{3}$ \\ Frederic Meyer ${ }^{4}$ \\ Joachim Enax ${ }^{4}$ \\ 'Department of Comprehensive \\ Dentistry, School of Dentistry, University \\ of Texas Health San Antonio, San \\ Antonio, TX, 78229-3900, USA; \\ ${ }^{2}$ Department of Biology, University of \\ Texas at San Antonio, San Antonio, TX, \\ USA; ${ }^{3}$ Department of Restorative \\ Dentistry, Faculty of Dentistry, College of \\ Medicine, University of Nigeria, Enugu, \\ Nigeria; ${ }^{4}$ Research Department, Dr. Kurt \\ Wolff GmbH \& Co. KG, Bielefeld, \\ Germany
}

Purpose: The effectiveness of a hydroxyapatite (HAP) toothpaste and a fluoride toothpaste in preventing root tissue demineralization (root caries) was compared using an established pH-cycling caries model.

Materials and Methods: Sixty dentin blocks were produced from the root tissue of extracted human teeth and were assigned to 3 test groups ( $n=20 /$ group): $10 \%$ hydroxyapatite toothpaste (HAP), $1450 \mathrm{ppm}$ fluoride toothpaste (fluoride), and artificial saliva (artsaliva). Early root caries lesions were developed in each sample by 7-day demineralization using a pH-cycling caries model. The daily cyclic treatment regimen consists of two 2-minute

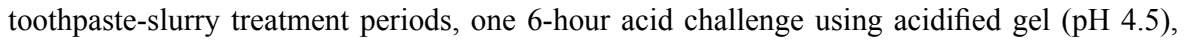
and then storage in remineralizing solution (artsaliva) for the rest of the time. Demineralization was assessed as the amount of mineral loss $(\Delta \mathrm{z})$ using transverse microradiography (TMR). Pairwise comparisons (between treatments) were performed using analysis of variance (ANOVA), and then Tukey's HSD for multiple comparisons. All $\mathrm{p}$-values are considered significant if $\mathrm{p}<0.05$.

Results: Both ANOVA and Tukey's HSD indicated no significant (ANOVA; $n=20$ ) difference in mean $\Delta z$ among the groups, with least $\Delta z( \pm S d)$ in the HAP $(1117 \pm 366)$ compared to fluoride (1392 \pm 334$)$ and artsaliva (1406 \pm 223$)$. Relative to control, HAP and fluoride inhibited root demineralization by $21 \%$ and $6 \%$, respectively.

Conclusion: Within the limit of the present study, the tested toothpaste containing $10 \%$ HAP is an effective root caries control toothpaste. Toothpaste containing 10\% HAP was slightly more effective in preventing tooth demineralization than $1450 \mathrm{ppm}$ fluoride provided as sodium fluoride. Thus, this study shows that HAP toothpastes can serve as an effective alternative to fluoride toothpastes for root caries management.

Keywords: hydroxyapatite, fluoride, $\mathrm{pH}$ cycling, artificial saliva, demineralization, toothpaste

\section{Introduction}

Root caries is one of the main upcoming issues in dentistry. ${ }^{1,2}$ Interestingly, measuring the exact prevalence of root caries is challenging, as the studies that have been performed are focusing on certain risk groups, thus leading to a bias when comparing the data. ${ }^{1}$ However, there is clear consensus that root caries is a growing concern in oral health. ${ }^{3}$

Individuals now retain their teeth longer in life due to wide availability of preventive and therapeutic oral care products, increased awareness of the importance of good oral hygiene as well as the current increased life expectation. ${ }^{4,5}$ This is creating new challenges for dental treatments. One of those challenges is the
Correspondence: Bennett Tochukwu Amaechi

Department of Comprehensive Dentistry, School of Dentistry, University of Texas Health San Antonio, 7703 Floyd Curl Drive, San Antonio, TX, 78229-3900, USA

Tel + I 2105673185

Email amaechi@uthscsa.edu 
exposure of root surfaces due to gingival recession, consequent to periodontal diseases. ${ }^{6,7}$ Tooth root is made of dentin that consists of approximately $70 \%$ inorganic materials and $30 \%$ organic matrix and water, unlike the enamel that is made of about $97 \%$ inorganic mineral and $3 \%$ organic materials and water. The inorganic materials of the dentin and enamel is the hydroxyapatite. While the crystal sizes of this naturally occurring hydroxyapatite are reported to be 160 to $1000 \mathrm{~nm}$ length, 40 to $120 \mathrm{~nm}$ width, and $25 \mathrm{~nm}$ thickness in tooth enamel, it is about $50 \mathrm{~nm}$ length, $20 \mathrm{~nm}$ width, and $2-5 \mathrm{~nm}$ thickness in dentin. ${ }^{8}$ These factors make dentin less mineralized compared to enamel, and as such more susceptible to acid dissolution compared to enamel (critical pH for enamel and dentin dissolution are 5.5 and 6.2, respectively). ${ }^{9,10}$ Consequently, root surfaces are more prone to develop cavities compared to enamel. ${ }^{11}$ Thus, root caries is an increasing clinical problem, and as such demands effective preventive strategies. $^{12}$

Fluoride interventions have the most consistent benefit in caries control with the highest level of supporting evidence. $^{13-15}$ However, there are limited data on the relative preventive and therapeutic effects of fluoride on dentin. ${ }^{16,17}$ There are research evidences supporting tooth brushing with high-fluoride dentifrice (5000 ppm F) to be more effective in controlling root caries, ${ }^{18-20}$ but high-fluoride toothpastes with 5000 ppm fluoride are only available by prescription from dentists. A recommended alternative is the combination of a standard fluoride dentifrice (1100 ppm F) and a professional fluoride application such as fluoride varnish, fluoride gel or $38 \%$ silver diamine fluoride. ${ }^{16,17,21-}$ 24 Thus the current recommendation for prevention of root caries entails the individual having access to a dentist. Besides, fluorides, in general, need calcium and phosphate ions to be effective in preventing and remineralizing the tooth surface. ${ }^{25,26}$ Thus, it is envision that a caries preventive formulations that provide additional calcium and phosphate ions to enhance the preventive potential of saliva may be more effective for prevention of root caries.

Today, toothpastes and other oral care products with calcium phosphates, such as microcrystalline hydroxyapatite, have been studied intensively. ${ }^{27-32}$ Several clinical, in situ and in vitro studies have demonstrated the efficacy of hydroxyapatite in preventing the development of dental caries and remineralizing initial caries lesions. ${ }^{27,28,31-33}$ Furthermore, particulate hydroxyapatite has been shown to be a calcium-releasing and a $\mathrm{pH}$ buffering agent, ${ }^{30}$ and as such it is envisioned to enhance the caries protective effect of saliva.

Therefore, the present study investigated the effectiveness of toothpaste containing hydroxyapatite (HAP) in preventing root tissue demineralization (root caries), comparing it with a standard fluoride toothpaste containing $1450 \mathrm{ppm}$ fluoride as sodium fluoride $(\mathrm{NaF})$. This will be conducted using a net-demineralization $\mathrm{pH}$-cycling caries model with objective measurement of mineral loss using transverse microradiography (TMR). ${ }^{34-36}$ Our null hypothesis was that there would be no statistically significant difference between HAP-containing toothpastes and the standard fluoride toothpaste in preventing root tissue demineralization.

\section{Materials and Methods Specimen Preparation}

This study was conducted in accordance with the ethical standards outlined in the 1964 Declaration of Helsinki and its later amendments. Following the approval of the Institutional Review Board (IRB Approval \#: HSC20080233N) of the University of Texas Health San Antonio (UTHSA), written informed consent was obtained from patients undergoing teeth extraction in the UTHSA oral surgery clinic, permitting the authors to collect the extracted teeth of the individual patients. Unidentifiable sound human teeth extracted due to either orthodontic or third-molar impaction reasons, and appropriately disposed in various clinics of UTHSA School of Dentistry, were collected and autoclaved $\left(121^{\circ} \mathrm{C}\right.$ for 15 minutes), and the root surfaces were planned to remove the cementum from the root surfaces. Using a water-cooled diamond wire saw (Walter Ebner, Switzerland), three dentin block $(\approx 3 \mathrm{~mm}$ length $\times 3 \mathrm{~mm}$ width $\times 2 \mathrm{~mm}$ thickness) were cut from the cervical region of the root of each of the 20 teeth used. A total of 60 dentin blocks were produced. The surfaces of each block were coated with two layers of acid-resistant nail varnish, except one exposed surface (3 $\mathrm{mm}$ x $3 \mathrm{~mm}$ ). Prior to use the specimens were stored at $100 \%$ relative humidity at $4^{\circ} \mathrm{C}$.

\section{Preparation of Treatment Solutions}

Standard remineralization solution and demineralization gel were prepared as described in our previous publications. ${ }^{34,35}$ The composition of the artificial saliva (AS) that served the dual functions of simulated saliva and remineralization 
solution is shown in Table 1. The demineralization gel (DG) was prepared by adding $0.1 \mathrm{M}$ sodium hydroxide solution to $0.1 \mathrm{M}$ lactic acid solution to give a solution with a final $\mathrm{pH}$ value of 4.5 . This solution was gelled by adding $6 \% \mathrm{w} / \mathrm{v}$ hydroxyethyl cellulose to it with vigorous stirring until a final consistency achieved has viscosity in the region of $100 \mathrm{cP}$. The AS and DG were stored in sealed containers at room temperature until used.

\section{Test Products and Study Groups}

The test and the control toothpaste formulations were provided in blinded tubes coded (A and B) by the sponsoring company, thus blinding the investigators until the completion of the study and data interpretation. The names, composition and manufacturers of the toothpaste formulations are shown in Table 1.

Using computer-generated randomization numbers from the biostatistics team, each of the three dentin blocks from each tooth was randomly assigned to one of 3 treatment groups (20 blocks/group): artificial saliva (AS), slurry of toothpaste containing $10 \%$ hydroxyapatite (HAP) or 1450 ppm fluoride $(\mathrm{NaF})$. Using a laboratory stand mixer, the toothpaste slurry was produced as a homogeneous mix of 1 part toothpaste and 3 parts $\mathrm{AS}$. The $\mathrm{pH}$ of each toothpaste formulation was measured and recorded. With dental heavy duty putty, the 20 blocks in each group were fixed in grooves carved in a cylindrical acrylic rod attached to the cover of a $250-\mathrm{mL}$ treatment tube.

\section{$\mathrm{pH}$ Cycling Regimen}

The pH-cycling regimen employed in this study was fully described in our previous publications. ${ }^{34,35}$ The samples were stored in AS with constant gentle rotation in the first
24 hours, and then $\mathrm{pH}$ cycling started the next day. The 3 groups were subjected to demineralization-remineralization cycles using a net demineralization pH-cycling model (Caries Prevention or Anticaries model). The cyclic treatment regimen for each day consisted of two 2-minute toothpaste slurry treatments, one 6-hour acid challenge in $\mathrm{DG}$, and then storage in AS for the rest of the time, including night (Table 2). For treatment, the sample-bearing cylindrical rod was immersed in $200 \mathrm{~mL}$ of the treatment medium (AS, DG or toothpaste slurry) in a $250 \mathrm{~mL}$ treatment tube. Although the AS group was stored in artificial saliva for the rest of the time like the other two groups, during demineralization and remineralization treatments it was immersed into DG and fresh AS, respectively. Artificial saliva treatment was magnetically stirred at $350 \mathrm{rpm}$, while the DG and toothpaste slurry were static. All treatments were carried out in an incubator at $37^{\circ} \mathrm{C}$. The specimens were rinsed with running deionized water after treatment with each medium, and mopped with paper towel before immersion into the medium. The daily regimen was performed for 7 days. On termination of the experiment, the dentin blocks were harvested and processed for demineralization assessment using Transverse Microradiography (TMR).

\section{Post-Treatment Samples Analysis}

On conclusion of the $\mathrm{pH}$-cycling, tooth sections $(\sim 150 \mu \mathrm{m}$ thick) were cut from each sample using hard tissue microtome (Leica Biosystems Nussloch GmbH 2021). The tooth sections were processed for TMR as described in our previous study. ${ }^{32}$ Briefly, the two cut sides of each section were polished with $6 \mu \mathrm{m}$ lapping film in a MultiPrep ${ }^{\mathrm{TM}}$ Precision Polishing machine (Allied High Tech, USA) to achieve

Table I The Names, Composition and Manufacturers of Test Products

\begin{tabular}{|c|c|c|}
\hline Product Names & Composition & Manufacturers \\
\hline Karex toothpaste & $\begin{array}{l}\text { I0\% hydroxyapatite, aqua, hydrated silica, glycerin, hydrogenated starch hydrolysate, } \\
\text { xylitol, silica, cellulose gum, sodium methyl cocoyl taurate, sodium sulfate, } \\
\text { I,2-hexanediol, caprylyl glycol, aroma, sodium cocoyl glycinate }\end{array}$ & $\begin{array}{l}\text { Dr. Kurt Wolff GmbH \& Co. } \\
\text { KG, Bielefeld, Germany }\end{array}$ \\
\hline Colgate toothpaste & $\begin{array}{l}0.32 \% \text { sodium fluoride ( } 1450 \mathrm{ppm} \text { fluoride), aqua, sorbitol, hydrated silica, glycerin, } \\
\text { sodium lauryl sulfate, peg-12, aroma, cellulose gum, sodium saccharine, Cl74I60, } \\
\mathrm{Cl} 74260, \mathrm{Cl} 7789 \mathrm{I}\end{array}$ & $\begin{array}{l}\text { Colgate-Palmolive GABA } \\
\text { GmbH, Hamburg, Germany }\end{array}$ \\
\hline $\begin{array}{l}\text { Artificial saliva/ } \\
\text { remineralization } \\
\text { solution }\end{array}$ & $\begin{array}{l}\mathrm{MgCL}_{2} \cdot 6 \mathrm{H}_{2} \mathrm{O}(0.148 \mathrm{mmol} / \mathrm{L}), \mathrm{K}_{2} \mathrm{HPO}_{4}(4.59 \mathrm{mmol} / \mathrm{L}), \mathrm{KH}_{2} \mathrm{PO}_{4}(2.38 \mathrm{mmol} / \mathrm{L}), \mathrm{KCL} \\
(8.39 \mathrm{mmol} / \mathrm{L}), \mathrm{NaCL}(14.37 \mathrm{mmol} / \mathrm{L}), \text { Calcium lactate }(1.76 \mathrm{mmol} / \mathrm{L}) \text {, Sodium } \\
\text { Carboxymethylcellulose }(2.25 \mathrm{mmol} / \mathrm{L}) \text {, and Methyl-4-hydroxybenzoate }(13.14 \mathrm{mmol} / \\
\mathrm{L}) \text {, with the } \mathrm{pH} \text { adjusted to } 7.2 \mathrm{using} \mathrm{KOH}\end{array}$ & Custom-made \\
\hline
\end{tabular}


Table $2 \mathrm{pH}$ Cycling Treatment Sequence for the Experiment

\begin{tabular}{|l|l|}
\hline Time & Treatment \\
\hline $\begin{array}{l}\text { Day I is all-day storage in remineralization solution. Then, subsequent } \\
\text { days' treatments will be as follows }\end{array}$ \\
\hline $\begin{array}{l}2 \text { min (starts 8:00 am) Approximately I hr } \\
\text { to complete all groups. }\end{array}$ & Toothpaste treatment \\
\hline Rinse with deionized distilled water & Acid challenge \\
\hline 6 hr (9:00 am - 3:00 pm) & Demineralization) \\
\hline Rinse with deionized distilled water & $\begin{array}{l}\text { Toothpaste treatment } \\
\text { to complete all groups. }\end{array}$ \\
\hline Rinse with deionized distilled water & $\begin{array}{l}\text { Remineralization } \\
\text { solution }\end{array}$ \\
\hline 16 hrs (From 4:00 pm till 8:00 am next day) & Storage in \\
\hline Repeated for 6 additional Days & \\
\hline
\end{tabular}

planoparallel surfaces as well as to reduce the thickness of the section to $100 \mu \mathrm{m}$ (the appropriate thickness for TMR). Following this, the sections were microradiographed on type 1A high-resolution glass X-ray plates (Microchrome Technology, CA, USA) using a Phillips x-ray generator system (Panalytical, Amsterdam). The plates were exposed for 10 minutes at an anode voltage of $20 \mathrm{kV}$ and a tube current of $10 \mathrm{~mA}$. Subsequently, the plates were processed by a 5-minute development in Kodak HR developer and 5-minute fixation in Kodak Rapid-fixer before a final washing in a running water for 30 minutes. Following drying of the plates, the microradiographs were examined under with a Leica DMR optical microscope linked via a Sony model XC-75CE CCTV camera to a computer housing the TMR image analysis software (TMR2006 version 3.0.0.6, Inspektor Research, Amsterdam). The captured image of the tooth sections was analyzed with the TMR program under standardized light intensity and magnification, along with data from the image of the step wedge. Using the software, the integrated mineral loss $(\Delta \mathrm{z}, \mathrm{vol} \% \mu \mathrm{m})$ was calculated as previously described. ${ }^{36}$

\section{Power Analysis and Sample Size Calculation}

The sample size, which was based on power analysis, was calculated with nQuery Advisor software (Statistical
Solutions, Cork, Ireland). In our previous similar $\mathrm{pH}-$ cycling study, the mean \% inhibition of mineral loss relative to control was equal to 19.69 with a standard deviation equal to $2.82,{ }^{35}$ and for the hypothesis that the two toothpaste formulations would prevent root tissue demineralization equally, an effective sample size of 20 blocks would have power greater than 0.85 with a 0.05 one-sided significance level to detect a difference in \% inhibition of mineral loss between the two formulations equal to or greater than $10 \%$ using a two-sided $t$-test of two independent means.

\section{Calculation of Percentage of Demineralization Inhibition and Statistical Analysis}

The $\%$ inhibition was calculated relative to the negative control group (AS group). For each of the 20 teeth used in the study, 3 dentin blocks were produced to give total of 60 blocks. For each of the tooth used, the mineral loss of the block in the toothpaste group (HAP or $\mathrm{NaF}$ ) was subtracted from the mineral loss of the block in the control (AS) group, and the difference was divided by the mineral loss of the block in the AS group. The product was then multiplied by 100 to obtain the $\%$ demineralization inhibition for that tooth for either HAP or AS group. The data generated were used to statistically compare the two test groups (HAP and $\mathrm{NaF}$ ) based on their \% demineralization inhibition.

Stata software version 11.0 (StataCorp, College Station, TX) statistical software was used. The mineral loss were normally distributed $(p>0.05)$ across the three treatment groups (HAP toothpaste, fluoride toothpaste, and artificial saliva) as assessed by Shapiro-Wilk's test. The null hypothesis that the HAP-containing toothpastes would be equally effective to standard fluoride toothpaste in decreasing mineral loss from dentin tissue was tested using Analysis of Variance (ANOVA). The efficacy and any significant difference among the 3 treatment groups in inhibiting demineralization of root tissue was determined using Tukey's HSD for multiple comparisons. All p-values were 2-sided and considered significant if less than 0.05 .

\section{Results}

Throughout the study period, the $\mathrm{pH}$ of the toothpaste slurries and the artificial saliva ranged from 7.2 to 7.4. Both ANOVA and Tukey's HSD indicated no significant $(\mathrm{n}=20)$ difference in mean $\Delta \mathrm{z}$ among the treatment groups 
(Table 3). However, numerically there are less mineral loss with HAP-containing toothpaste when compared to fluoride-containing toothpaste (Table 3). Relative to the control (AS) group, the HAP and the fluoride toothpaste inhibited root demineralization by $21 \%$ and $6 \%$, respectively. Examination of the TMR microradiograms from the 3 treatment groups showed mineralized surface layer with fluoride toothpaste but not with HAP toothpaste or AS. There was surface enamel breakdown in samples treated with AS but not in those treated with HAP and fluoride toothpaste (Figure 1).

\section{Discussion}

With increased life expectancy and awareness of the importance of good oral hygiene, with the wide availability of preventive and therapeutic oral care products, ${ }^{5}$ many adults are now retaining most of their teeth throughout life. ${ }^{4}$ Thus, more root surfaces become physiologically or pathologically exposed, and as such at risk of developing dental caries. ${ }^{37,38}$ Therefore, there is a need for development of effective preventive strategies for root caries. Previous clinical, in situ and in vitro studies have established hydroxyapatite crystals in toothpaste and mouthrinse to be as effective as fluoride in reducing tooth demineralization as well as promoting caries remineralization. ${ }^{28,31,33,39,40}$ For this reason, the present study investigated and compared the effectiveness of a HAP-based toothpaste with that of a standard non-prescription toothpaste containing $1450 \mathrm{ppm}$ fluoride $(\mathrm{NaF})$ in preventing root dentin demineralization (root caries). The daily use of the toothpaste was simulated using a netdemineralization $\mathrm{pH}$-cycling caries model (caries prevention or anticaries model). Because a $\mathrm{pH}$-cycling model mirrors clinical conditions, where demineralization and remineralization alternate constantly (ie $\mathrm{pH}$ cycling), it can be considered as a bridge to in vivo caries studies. ${ }^{34}$ The cycle is only interrupted during the short period of application of investigational products, such as toothpaste or mouthrinse. Employed in the present study is the long established Featherstone laboratory $\mathrm{pH}$ cycling model (Table 2), which is considered the "Gold Standard" model in $\mathrm{pH}$ cycling study. ${ }^{41,42}$ This model was developed at the request of the Food \& Drug Administration (FDA), and was accepted as a non-animal alternative to animal caries reduction test for demonstration of efficacy of "Anticaries dentifrice product formulations" for over-thecounter human use. ${ }^{41,42}$ Although this model lacks the cariogenic dental plaque, which is a key factor in the caries process, the alternating feast and famine episodes that occur in bacterial plaque in the oral cavity are mimicked by alternating exposure of the root dentin to demineralization and remineralization solutions. ${ }^{43}$ With this model, 9 and 14 days cycling period were recommended for bovine and human enamel, respectively, however, considering that dentin (root tissue) is less mineralized and as such more susceptible to caries than enamel, ${ }^{44}$ the treatment was performed for only 7 days as shown in Table 2.

With either the percentage inhibition of demineralization or the amount of mineral loss (Table 3 ), the effectiveness of the two toothpaste formulations in preventing root caries development were not statistically significant, thus accepting our hypothesis that there would be no statistically significant difference between HAP-containing toothpastes and

Table 3 Mean $( \pm S D)$ Values of Mineral Loss $(\Delta Z)$ in Each Treatment Group and Percentage Inhibition of Demineralization by Each of the Two Toothpaste Formulations Relative to the Untreated Control (Artificial Saliva)

\begin{tabular}{|c|c|c|c|c|c|c|}
\hline & $\begin{array}{l}\text { Artificial } \\
\text { Saliva }\end{array}$ & $\begin{array}{l}\text { 10\% Hydroxyapatite } \\
\text { Toothpaste }\end{array}$ & $\begin{array}{l}\text { I } 450 \text { ppm Fluoride } \\
\text { Toothpaste ( } \mathrm{NaF})\end{array}$ & $\begin{array}{l}\text { Mean } \\
\text { Diff }\end{array}$ & $\begin{array}{l}95 \% \mathrm{Cl} \\
\text { of Diff }\end{array}$ & $\begin{array}{l}P \text { value } \\
(P<0.05)\end{array}$ \\
\hline \multirow[t]{3}{*}{ Mean $\pm S D(95 \% \mathrm{Cl})$} & $\begin{array}{l}1406 \pm 223 \\
(1234-\mid 577)\end{array}$ & $1117 \pm 366(855-1379)$ & - & 289 & $\begin{array}{l}-74 \text { to } \\
651\end{array}$ & Ns \\
\hline & $\begin{array}{l}1406 \pm 223 \\
(1234-1577)\end{array}$ & - & $1392 \pm 334(104 \mid-1742)$ & 14 & $\begin{array}{l}-401 \text { to } \\
429\end{array}$ & Ns \\
\hline & - & $1117 \pm 366(855-1379)$ & $1392 \pm 334(104|-| 742)$ & -275 & $\begin{array}{l}-682 \text { to } \\
132\end{array}$ & Ns \\
\hline $\begin{array}{l}\% \text { inhibition of } \Delta Z \text { relative } \\
\text { to control }\end{array}$ & - & $21 \pm 8.9 \%$ & $6 \pm 9.8 \%$ & $\begin{array}{l}15 \pm \\
14\end{array}$ & -14 to 44 & Ns \\
\hline
\end{tabular}

Abbreviation: ns, not significantly different. 


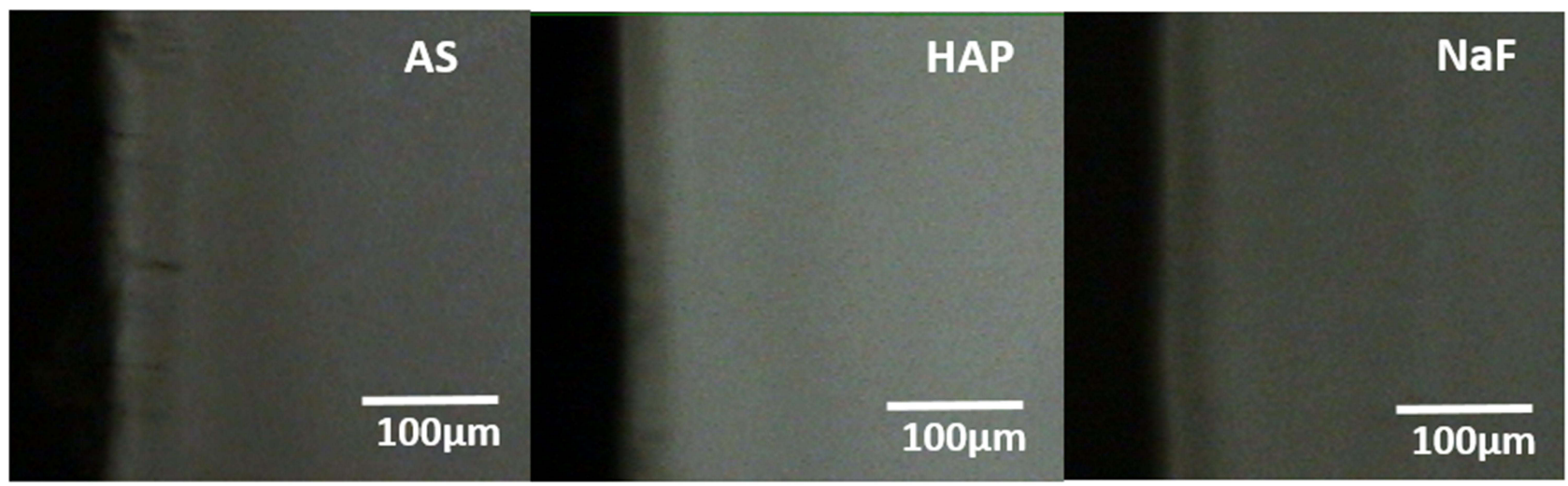

Figure I Representative microradiographic images from the 3 treatment groups showed mineralized surface layer with fluoride (NaF) toothpaste (I450 ppm fluoride) but not with hydroxyapatite (HAP) toothpaste (10\% HAP microclusters) or artificial saliva (AS). There was surface enamel breakdown in samples treated with AS but not in those treated with HAP and $\mathrm{NaF}$ toothpaste.

the standard fluoride toothpaste in preventing root tissue demineralization. This observation confirmed the reports of previous studies in which the non-inferiority of HAP to fluoride in prevention and remineralization of enamel caries was demonstrated in three clinical studies and a similar $\mathrm{pH}$ cycling study. ${ }^{28,31,32,39}$ Two randomized controlled trial demonstrated the non-inferiority of $10 \%$ HAP toothpaste to $1400 \mathrm{ppm}$ and $500 \mathrm{ppm}$ fluoride toothpaste respectively, ${ }^{28,39}$ while an in situ study reported non-inferiority of $10 \%$ HAP toothpaste to $500 \mathrm{ppm}$ fluoride toothpaste. $^{31}$ The $\mathrm{pH}$ cycling study showed the non-inferiority of $15 \%$ HAP oral care gel to $12,500 \mathrm{ppm}$ fluoride gel. ${ }^{32}$ However, these studies on enamel caries, like other non-inferiority studies, set their non-inferiority margin at $20 \%$, indicating that above $20 \%$, superiority may be established. Hence, with $21 \%$ as opposed to $6 \%$ inhibition of demineralization by $10 \%$ HAP and $1450 \mathrm{ppm}$ fluoride toothpaste respectively, one may argue that with respect to root caries prevention 10\% HAP toothpaste was more effective than $1450 \mathrm{ppm}$ fluoride toothpaste. However, this would have to be confirm in a randomized clinical trial. Other clinical and in vitro studies has also reported equal effectiveness of HAP and fluoride in caries control. ${ }^{40,43}$ The observed $21 \%$ inhibition of demineralization by HAP in the present study is in agreement with previous studies that demonstrated the effectiveness of toothpaste containing varying percentages of HAP in inhibiting tooth tissue demineralization. ${ }^{27,28,31,39,40}$ This effect of HAP has been attributed to several characteristics of the synthetic particulate HAP, which determines its mode of actions. Synthetic HAP in nanocrystalline or microcluster forms shows a high similarity to the mineral phase of human teeth, and it is bioactive and biocompatible with a strong affinity to tooth tissues. ${ }^{10,27,29}$ The multiple mechanisms by which the HAP exhibits its caries preventive function has been established in previous studies. ${ }^{28}$ When used as toothpaste, HAP elevates the calcium and phosphate ions concentrations on tooth surfaces, ${ }^{27,30,45-47}$ thereby acting as a reservoir of calcium and phosphate to help in maintaining a topical state of supersaturation of these ions with respect to tooth minerals. ${ }^{45-47}$ This highlights the potential of this active ingredient to influence demineralization process on tooth surface. It has also been postulated that during acidic challenge the dissociation products of HAP, in particular, the phosphate ions, are able to neutralize acids to a certain level, thereby serving as a buffering agent like the salivary phosphate-buffer. ${ }^{10,27}$ Also, the released calcium and phosphate ions, when present in excess, can promote remineralization by switching the solubility product balance. ${ }^{27}$ Furthermore, the $\mathrm{pH}$ cycling model used in the present study is a demineralization-remineralization system, and as such the remineralization process must have contributed to limiting the amount of mineral loss in the demineralization process. The effectiveness of HAP in remineralizing caries lesion has been supported by a lot of research evidence. ${ }^{31-}$ $33,40,48-51$ In net remineralization $\mathrm{pH}$ cycling study $10.56 \%$ and $9.58 \%$ remineralization, was reported for $10 \%$ HAP and $1450 \mathrm{ppm}$ amine fluoride toothpastes respectively. ${ }^{52}$ Also in a previous similar study, 10\% HAP toothpaste and $1.23 \%$ acidulated phosphate fluoride gel effected $46.27 \%$ and $28.84 \%$ remineralization respectively. ${ }^{53}$ Particulate HAP induce remineralization by directly filling micropores in demineralized tooth tissue, ${ }^{48,54}$ where it acts as a crystal nucleus to promote crystal deposition and growth by 
continuously attracting large amounts of calcium and phosphate ions from the surrounding fluids. ${ }^{54,55}$ In the present study, the root tissue was subjected to an aggressive 6 hours continuous acidic challenge each day, while the rest 18 hours was remineralization by either toothpaste or artificial saliva. Thus it is believed that is remineralization action contributed to the $21 \%$ inhibition of demineralization observed in the present study.

Furthermore, HAP applied as a desensitizing toothpaste or cream on exposed root surface has been shown to relieve sensitivity by occluding the dentin tubules by deposition of calcium phosphate within the tubules and on the surface of the root dentin. ${ }^{56-58}$ It is believed that this mechanism may have contributed to the demineralization inhibition by HAP observed in the present study. Moreover, considering that HAP was able to effect $21 \%$ demineralization inhibition, despite the high acidic challenge ( $\mathrm{pH} 4.5$ ) of daily 6 hours continuous demineralization employed in the present study, and which is not obtainable in vivo, it can be postulated that $10 \%$ HAP toothpaste used routinely in oral hygiene procedure would prevent root caries, even in high caries risk condition that was modeled with the 6 hours demineralization. However, this needs to be confirmed in a clinical trial.

Although there are strong evidences supporting the effect of fluoride dentifrice on enamel caries, ${ }^{59,60}$ there are limited data on the relative preventive and therapeutic effects of fluoride on dentin. ${ }^{16,17}$ Previous studies pointed to the direction that the strength of the fluoride effect on dentin is different from that on enamel. ${ }^{21,61}$ Combination of standard fluoride dentifrice (1100 ppm F) and professional fluoride applications (varnish, gel, 38\% SDF) was recommended for control of dentin caries. ${ }^{16,17,21,22}$ A review of clinical trials reported that standard fluoride toothpaste was only able to produce caries reduction (average $21 \%$ ) when daily toothpaste use was complemented with fluoride gels. ${ }^{62}$ Thus, the $6 \%$ inhibition of demineralization observed with only standard fluoride toothpaste (1450 ppm) in the present study was not unexpected. Evidence exists that high-fluoride dentifrice (5000 ppm F) is more effective in controlling root caries in elderly people than toothpaste containing either 1100 ppm or 1450 ppm F. ${ }^{18-20}$

Consistent with the observations in previous studies is the appearance of a mineralized surface layer in the fluoride group in the present study (Figure 1), which is known to be associated with the presence of fluoride. It is expected that the mineralized tissue would limit the acid diffusion into the tooth tissue, however, in dentin the interface with cariogenic acids is larger than in enamel, ${ }^{63}$ and as such acids may bypass the mineralized surface layer to effect more demineralization. It is also believed that this mineralized layer may also limit the rate of diffusion of mineral ions to effect remineralization, which as discussed above helps to reduce the rate of demineralization. Furthermore, usually the demineralization solutions used for creation of caries-like lesions are partially saturated with small amount of mineral ions (including $\mathrm{NaF}$ ) to preserve the dentin surface integrity, ${ }^{21}$ but the demineralization gel used in present study is devoid of any mineral element, hence the rapid demineralization within 7 days. The authors strongly believed that this lack of partial saturation of the demineralization gel was responsible for the absence of mineralized surface layer in both the HAP and AS groups, and the presence of the surface enamel breakdown observed in samples from AS group (Figure 1). However, the absence of this surface enamel breakdown in samples from the HAP group, despite the use of "notpartially-saturated" demineralization gel, is a further evidence of the modulating effect of the HAP on the rate of demineralization, which can be attributed to the presence of calcium and phosphate ions provided through dissociation of the HAP particles under acidic challenge. Furthermore, the absence of mineralized surface layer indicates that there was no limitation to the rate of remineralization that helps to reduce the rate of demineralization, unlike the situation with fluoride where the mineralized surface layer may have reduced the rate of remineralization, as discussed above. Thus, the absence of mineralized surface layer may also have contributed to the greater percentage of demineralization inhibition effected by the HAP toothpaste. These factors contributed to the superiority of HAP toothpaste over fluoride toothpaste, despite lack of significant difference with respect to the amount of mineral loss.

Although the present model was able to demonstrate inhibitory effect of HAP toothpaste on root caries, further studies are needed to evaluate the effect of complementing the use of $10 \%$ HAP toothpaste (twice daily) with application of $15 \%$ HAP gel (once daily) to confirm which regime would be clinically more applicable and more effective for preventing root caries. ${ }^{32}$

A main limitation of the present study is the lacks the biological processes within the oral cavity, particularly within the dental plaque milieu, which would undoubtedly influence 
the demineralization inhibitory potential of the investigational products. Furthermore, a more aggressive demineralization process than the acid attacks the tooth is exposed in the oral cavity was used in $\mathrm{pH}$ cycling. Future research to further establish the effectiveness of HAP-based toothpaste to prevent root caries should focus on clinical trials.

\section{Conclusions}

Under the present net-demineralization $\mathrm{pH}$-cycling conditions, the tested fluoride-free toothpaste containing $10 \%$ HAP was demonstrated to be an effective dentin caries control tool. Although effected a higher percentage of demineralization inhibition, toothpaste containing $10 \%$ HAP was not statistically more effective than standard $\mathrm{NaF}$ toothpaste with $1450 \mathrm{ppm}$ fluoride in preventing root dentin demineralization. Thus, this study demonstrated that HAP toothpastes can serve as an effective alternative to fluoride toothpastes for root caries management.

\section{Acknowledgments}

The authors wish to thank the University Core Facility for help with the imaging of the tooth samples.

\section{Disclosure}

All authors report no conflicts of interest in this work.

\section{References}

1. Hayes M, Burke F, Allen PF. Incidence, Prevalence and Global Distribution of Root Caries. In: Carrilho MRO, editor. Root Caries: From Prevalence to Therapy. Vol. 26. Karger; 2017:1-8.

2. Heinrich R, Heinrich J, Künzel W. [Will root caries become a treatment problem of the future?] Zahn Mund Kieferheilkd Zentralbl. 1990;78:253-257. German

3. Walls A. Aging-a call to arms! J Dent Res. 2017;96:721-722. doi: $10.1177 / 0022034517712436$

4. Fure S. Ten-year cross-sectional and incidence study of coronal and root caries and some related factors in elderly Swedish individuals. Gerodontology. 2004;21(3):130-140. doi:10.1111/j.17412358.2004.00025.x

5. Walls AW, Meurman JH. Approaches to caries prevention and therapy in the elderly. Adv Dent Res. 2012;24:36-40. doi:10.1177/ 0022034512453590

6. Bignozzi I, Crea A, Capri D, Littarru C, Lajolo C, Tatakis DN. Root caries: a periodontal perspective. J Periodontal Res. 2014;49 (2):143-163. doi:10.1111/jre.12094

7. Deliberador TM, Bosco AF, Martins TM, Nagata MJH. Treatment of gingival recessions associated to cervical abrasion lesions with subepithelial connective tissue graft: a case report. Eur $J$ Dent. 2009;3:318-323. doi:10.1055/s-0039-1697451

8. Robinson C, Connell S, Kirkham J, Shore R, Smith A. Dental enamel - a biological ceramic: regular substructures in enamel hydroxyapatite crystals revealed by atomic force microscopy. J Mater Chem. 2004;14 (14):2242-2248. doi:10.1039/B401154F
9. Mate Sanchez de Val JE, Calvo-Guirado JL, Gomez-Moreno G, Perez-Albacete Martinez C, Mazon P, De Aza PN. Influence of hydroxyapatite granule size, porosity, and crystallinity on tissue reaction in vivo. Part A: synthesis, characterization of the materials, and SEM analysis. Clin Oral Implants Res. 2016;27(11):1331-1338. doi: $10.1111 /$ clr.12722

10. Dorozhkin SV, Epple M. Biological and medical significance of calcium phosphates. Angew Chem Int Ed. 2002;41:3130-3146. doi:10.1002/ 1521-3773(20020902)41:17<3130::AID-ANIE3130>3.0.CO;2-1

11. Goldberg M. Enamel and dentin carious lesions. JSM Dent. 2020;8:1120.

12. Tan H, Richards $\mathrm{L}$, Walsh $\mathrm{T}$, et al. Interventions for managing root caries. Cochrane Database Syst Rev. 2017;2017(8):1-12. doi:10.1002/14651858.CD012750

13. Benson PE, Parkin N, Dyer F, Millett DT, Furness S, Germain P. Fluorides for the prevention of early tooth decay (demineralised white lesions) during fixed brace treatment. Cochrane Database Syst Rev. 2013;12:CD003809.

14. Walsh T, Worthington HV, Glenny AM, Marinho VC, Jeroncic A. Fluoride toothpastes of different concentrations for preventing dental caries. Cochrane Database Syst Rev. 2019;4(3):CD007868.

15. Shahid M. Regular supervised fluoride mouthrinse use by children and adolescents associated with caries reduction. Evid Based Dent. 2017;18:11-12. doi:10.1038/sj.ebd.6401217

16. Wierichs RJ, Meyer-Lueckel H. Systematic review on noninvasive treatment of root caries lesions. J Dent Res. 2015;94(2):261-271. doi: $10.1177 / 0022034514557330$

17. Meyer-Lueckel H, Machiulskiene V, Giacaman RA. How to intervene in the root caries process? Systematic review and meta-analyses. Caries Res. 2019;53(6):599-608. doi:10.1159/000501588

18. Baysan A, Lynch E, Ellwood R, Davies R, Petersson L, Borsboom P. Reversal of primary root caries using dentifrices containing 5000 and 1100 ppm fluoride. Caries Res. 2001;35:41-46.

19. Ekstrand KR, Poulsen JE, Hede B, Twetman S, Qvist V, Ellwood RP. A randomized clinical trial of the anti-caries efficacy of 5000 compared to $1450 \mathrm{ppm}$ fluoridated toothpaste on root caries lesions in elderly disabled nursing home residents. Caries Res. 2013;47 (5):391-398. doi:10.1159/000348581

20. Srinivasan M, Schimmel M, Riesen M, et al. High-fluoride toothpaste: a multicenter randomized controlled trial in adults. Community Dent Oral Epidemiol. 2014;42:333-340. doi:10.1111/cdoe.12090

21. Fernández CE, Tenuta LM, Del Bel Cury AA, Nóbrega DF, Cury JA. Effect of $5000 \mathrm{ppm}$ fluoride dentifrice or $1100 \mathrm{ppm}$ fluoride dentifrice combined with acidulated phosphate fluoride on caries lesion inhibition and repair. Caries Res. 2017;51:179-187. doi:10.1159/000453624

22. Erdwey D, Meyer-Lueckel H, Esteves-Oliveira M, Apel C, Wierichs RJ. Demineralization inhibitory effects of highly concentrated fluoride dentifrice and fluoride gels/solutions on sound dentin and artificial dentin caries lesions in vitro. Caries Res. 2021;55:41-54. doi:10.1159/000509931

23. Slayton RL, Urquhart O, Araujo MWB, et al. Evidence-based clinical practice guideline on non-restorative treatments for carious lesions: a report from the American Dental Association. JADA. 2018;149:837-849.

24. Mei ML, Chu CH, Lo ECM, Samaranayake LP. Fluoride and silver concentrations of silver diammine fluoride solutions for dental use. Int J Paediatr Dent. 2013;23:279-285. doi:10.1111/ipd.12005

25. Epple M, Enax J. The chemistry of dental care. Chem Views. 2018. doi: $10.1002 /$ chemv. 201800053

26. Ten Cate JM. Review on fluoride, with special emphasis on calcium fluoride mechanisms in caries prevention. Eur J Oral Sci. 1997;105 (5):461-465. doi:10.1111/j.1600-0722.1997.tb00231.x

27. Enax J, Fabritius HO, Fabritius-Vilpoux K, Amaechi BT, Meyer F. Modes of action and clinical efficacy of particulate hydroxyapatite in preventive oral health care - state of the art. Open Dent J. 2019;13:274-287. doi:10.2174/1874210601913010274 
28. Schlagenhauf U, Kunzelmann KH, Hannig C, et al. Impact of a non-fluoridated microcrystalline hydroxyapatite dentifrice on enamel caries progression in highly caries-susceptible orthodontic patients: a randomized, controlled 6-month trial. J Invest Clin Dent. 2019;10: e12399. doi:10.1111/jicd.12399

29. Fabritius-Vilpoux K, Enax J, Herbig M, Raabe D, Fabritius HO. Quantitative affinity parameters of synthetic hydroxyapatite and enamel surfaces in vitro. Bioinspir Biomim Nan. 2019;8:141-153.

30. Cieplik F, Rupp CM, Hirsch S, et al. $\mathrm{Ca}^{2}+$ release and buffering effects of synthetic hydroxyapatite following bacterial acid challenge. BMC Oral Health. 2020;20:85. doi:10.1186/s12903-020-01080-z

31. Amaechi BT, AbdulAzees PA, Alshareif DO, et al. Comparative efficacy of a hydroxyapatite and a fluoride toothpaste for prevention and remineralization of dental caries in children. BDJ Open. 2019;5:18. doi:10.1038/s41405-019-0026-8

32. Amaechi BT, AbdulAzees PA, Okoye LO, Meyer F, Enax J. Comparison of hydroxyapatite and fluoride oral care gels for remineralization of initial caries: a pH-cycling study. BDJ Open. 2020;6:9. doi:10.1038/s41405-020-0037-5

33. Tschoppe P, Zandim DL, Martus P, Kielbassa AM. Enamel and dentine remineralization by nano-hydroxyapatite toothpastes. J Dent. 2011;39:430-437. doi:10.1016/j.jdent.2011.03.008

34. Amaechi BT. Protocols to study dental caries in vitro: $\mathrm{pH}$ cycling models. In: Papagerakis $\mathrm{P}$, editor. Odontogenesis: Methods and Protocols. Chapter 34. Springer publishers; 2019:379-392.

35. Amaechi BT, Kasundra H, Joshi DJ, Abdollahi A, Azees PAA, Okoye LO. Effectiveness of S-PRG filler-containing toothpaste in inhibiting demineralization of human tooth surface. TODENTJ. 2018;12:811-819. doi:10.2174/1874210601812010811

36. De Josselin de Jong E, Ten Bosch JJ, Noordman J. Optimised microcomputer guided quantitative microradiography on dental mineralised tissue slices. Phys Med Biol. 1987;32:887-899. doi:10.1088/0031-9155/32/7/008

37. Ritter AV, Shugars DA, Bader JD. Root caries risk indicators: a systematic review of risk models. Community Dent Oral Epidemiol. 2010;38:383-397. doi:10.1111/j.1600-0528.2010.00551.x

38. Saunders RHJ, Meyerowitz C. Dental caries in older adults. Dent Clin North Am. 2005;49(2):293-308. doi:10.1016/j.cden.2004.10.004

39. Paszynska E, Pawinska M, Gawriolek M, et al. Impact of a toothpaste with microcrystalline hydroxyapatite on the occurrence of early childhood caries: a 1-year randomized clinical trial. Sci Rep. 2021;11(1):2650. doi:10.1038/s41598-021-81112-y

40. Najibfard K, Ramalingam K, Chedjieu I, Amaechi BT. Remineralization of early caries by a nano-hydroxyapatite dentifrice. J Clin Dent. 2011;22:139-143.

41. Featherstone JD, Stookey GK, Kaminski MA, Faller RV. Recommendation for a non-animal alternative to rat caries testing. Am J Dent. 2011;24:289-294.

42. Stookey GK, Featherstone JD, Rapozo-Hilo M, et al. The Featherstone laboratory $\mathrm{pH}$ cycling model: a prospective, multi-site validation exercise. Am J Dent. 2011;24:322-328.

43. Gonçalves FMC, Delbem ACB, Pessan JP, et al. Remineralizing effect of a fluoridated gel containing sodium hexametaphosphate: an in vitro study. Arch Oral Biol. 2018;90:40-44. doi:10.1016/j. archoralbio.2018.03.001

44. Nyvad B, Fejerskov O. Root surface caries: clinical, histopathological and microbiological features and clinical implications. Int Dent J. 1982;32:311-326.

45. Sudradjat H, Meyer F, Loza K, Epple M, Enax J. In vivo effects of a hydroxyapatite-based oral care gel on the calcium and phosphorus levels of dental plaque. Eur J Dent. 2020;14(2):206-211. doi:10.1055/s-0040-1708456
46. Hornby K, Evans M, Long M, Joiner A, Laucello M, Salvaderi A. Enamel benefits of a new hydroxyapatite containing fluoride toothpaste. Int Dent J. 2009;59:325-331. doi:10.1002/ idj.2009.59.6s1.325

47. Schäfer F, Beasley T, Abraham P. In vivo delivery of fluoride and calcium from toothpaste containing 2\% hydroxyapatite. Int Dent J. 2009;59:321-324. doi:10.1002/idj.2009.59.6s1.321

48. Huang S, Gao S, Cheng L, Yu H. Remineralization potential of nano-hydroxyapatite on initial enamel lesions: an in vitro study. Caries Res. 2011;45(5):460-468. doi:10.1159/000331207

49. Juntavee N, Juntavee A, Plongniras P. Remineralization potential of nano-hydroxyapatite on enamel and cementum surrounding margin of computer-aided design and computer-aided manufacturing ceramic restoration. Int J Nanomedicine. 2018;13:2755-2765. doi:10.2147/ IJN.S165080

50. de Carvalho FG, Vieira BR, Santos RL, Carlo HL, Lopes PQ, de Lima BA. In vitro effects of nano-hydroxyapatite paste on initial enamel carious lesions. Pediatr Dent. 2014;36:85-89.

51. Swarup JS, Rao A. Enamel surface remineralization: using synthetic nanohydroxyapatite. Contemp Clin Dent. 2012;3:433-436. doi:10.4103/0976-237X.107434

52. Manchery N, John J, Nagappan N, Subbiah GK, Premnath P. Remineralization potential of dentifrice containing nanohydroxyapatite on artificial carious lesions of enamel: a comparative in vitro study. Dent Res J. 2019;16:310-317. doi:10.4103/1735-3327.266096

53. Alsherif AA, Elbardisy DM, Taiema DA. Efficacy of nanohydroxyapatite versus acidulated phosphate fluoride on initial demineralized enamel surface (in vitro Study). Egypt Dent J. 2017;63:781-790.

54. Pepla E, Besharat LK, Palaia G, Tenore G, Migliau G. Nano-hydroxyapatite and its applications in preventive, restorative and regenerative dentistry: a review of literature. Ann Stomatol. 2014;20:108-114.

55. Li L, Pan H, Tao J, et al. Repair of enamel by using hydroxyapatite nanoparticles as the building blocks. J Mater Chem. 2008;18 (34):4079-4084. doi:10.1039/b806090h

56. Hiller K-A, Buchalla W, Grillmeier I, Neubauer C, Schmalz G. In vitro effects of hydroxyapatite containing toothpastes on dentin permeability after multiple applications and ageing. Sci Rep. 2018;8 (1):4888. doi:10.1038/s41598-018-22764-1

57. Amaechi BT, Lemke KC, Saha S, Gelfond J. Clinical efficacy in relieving dentin hypersensitivity of nanohydroxyapatite-containing cream: a randomized controlled trial. Open Dent J. 2018;12 (1):572-585. doi:10.2174/1874210601812010572

58. Amaechi BT, Mathews SM, Ramalingam K, Mensinkai PK. Evaluation of nanohydroxyapatite-containing toothpaste for occluding dentin tubules. Am J Dent. 2015;28:33-39.

59. Amaechi BT, van Loveren C. Fluorides and non-fluoride remineralization systems. Monogr Oral Sci. 2013;23:15-26.

60. Marinho VC, Higgins JP, Sheiham A, Logan S. Fluoride toothpastes for preventing dental caries in children and adolescents. Cochrane Database Syst Rev. 2003;CD002278.

61. Petersson LG. The role of fluoride in the preventive management of dentin hypersensitivity and root caries. Clin Oral Investig. 2013;17 (suppl S1):S63-S71. doi:10.1007/s00784-012-0916-9

62. Marinho VC, Higgins JPT, Sheiham A, Logan S. Combinations of topical fluoride (toothpastes, mouthrinses, gels, varnishes) versus single topical fluoride for preventing dental caries in children and adolescents. Cochrane Database Syst Rev. 2004.

63. Buzalaf MA, Pessan JP, Honório HM, Ten Cate JM. Mechanisms of action of fluoride for caries control. Monogr Oral Sci. 2011;22:97-114. 


\section{Publish your work in this journal}

Clinical, Cosmetic and Investigational Dentistry is an international, peer-reviewed, open access, online journal focusing on the latest clinical and experimental research in dentistry with specific emphasis on cosmetic interventions. Innovative developments in dental materials, techniques and devices that improve outcomes and patient satisfaction and preference will be highlighted. The manuscript management system is completely online and includes a very quick and fair peer-review system, which is all easy to use. Visit http://www.dovepress.com/testimonials.php to read real quotes from published authors. 